Neuroembryology and Aging
Neuroembryol Aging 2006-07;4:165-174

DOI: $10.1159 / 000118926$
Received: June 12, 2007

Accepted: September 18, 2007

Published online: February 26, 2008

\title{
In utero Repair of Myelomeningocele: Rationale, Initial Clinical Experience and a Randomized Controlled Prospective Clinical Trial
}

\author{
Enrico Danzer Alan W. Flake \\ Center for Fetal Diagnosis and Treatment and Center for Fetal Research, The Children's Hospital of Philadelphia \\ and University of Pennsylvania School of Medicine, Philadelphia, Pa., USA
}

\section{Key Words}

Myelomeningocele $\cdot$ Fetus $\cdot$ Prenatal diagnosis $\cdot$ In utero repair - Management of Myelomeningocele Study (MOMS)

\begin{abstract}
Myelomeningocele (MMC), one of the most common congenital malformations, can result in severe lifelong disabilities, including paraplegia, hydrocephalus, Arnold-Chiari II malformation, incontinence, sexual dysfunction, skeletal deformations, and mental impairment. MMC was the first nonlethal anomaly to be treated by fetal surgery. Studies in animals provide compelling evidence that the primary cause of the neurological deficit associated with MMC is not simply incomplete neurulation but rather chronic mechanical injury and amniotic-fluid-induced chemical trauma that progressively damage the exposed neural tissue during gestation. Initial results suggest that the surgical repair of MMC before 25 weeks of gestation may preserve neurological function, reverse the hindbrain herniation of the ArnoldChiari II malformation, and obviate the need for postnatal placement of a ventriculoperitoneal shunt. As it is currently unknown whether fetal surgery for MMC is truly beneficial compared to standard postnatal care, a randomized, controlled clinical trial has been initiated within the United States.

Copyright $\odot 2008$ S. Karger AG, Basel
\end{abstract}

\section{Introduction}

Myelomeningocele (MMC) is a devastating congenital defect with sequelae that effect both the central and peripheral nervous system. The lesion is characterized by the protrusion of the spinal cord and meninges from the spinal canal with an abnormality in the overlying vertebral arches, muscle and skin. In most cases, MMC leads to lifelong severe physical and developmental disabilities including impaired mental development, bladder and bowel incontinence, sexual dysfunction, various skeletal deformities, and paraplegia [1]. In addition to motor and sensory deficits caused by the spinal cord lesion, significant problems in MMC arise from hydrocephalus, the Arnold-Chiari II malformation, and spinal cord tethering at the site of surgical repair. Approximately $85 \%$ of patients with thoracolumbar, lumbar, and lumbosacral MMC eventually develop hydrocephalus, requiring ventriculoperitoneal shunt placement to prevent the neurological and intellectual compromise that accompanies significant ventriculomegaly $[2,3]$. In addition, virtually all children with MMC also have the Arnold-Chiari II malformation, characterized by descent of the medulla, cerebellar tonsils and vermis through the foramen magnum, a small posterior fossa, 'beaking' of the midbrain tectum, enlarged massa intermedia of the thalamus, par-

\section{KARGER}

Fax +41613061234 E-Mail karger@karger.ch www.karger.com
Enrico Danzer, MD

Abramson Research Center, Center for Fetal Diagnosis and Treatment

The Children's Hospital of Philadelphia, Rm. 1112F

3615 Civic Center Blvd., Philadelphia, PA 19104-4318 (USA)

Tel. +1 215590 1210, Fax +1 215590 3324, E-Mail danzer@email.chop.edu 
tial or complete dysgenesis of the corpus callosum, and structural changes of the skull $[4,5]$. Clinical presentations of this malformation depend upon the age of the child, but typically it includes dysfunction of the cerebellum, medullary respiratory center and cranial nerve disturbances, as well as hydrocephalus [6, 7]. While the degree of hindbrain herniation and hydrocephalus are felt to be correlated, the exact pathophysiological mechanisms relating the two remain poorly understood. The leading 'unified' theory focuses on abnormal cerebrospinal fluid hydrodynamics with leakage of cerebrospinal fluid out of the spinal lesion causing downward movement of the hindbrain and obstruction of the normal egress of cerebrospinal fluid from the fourth ventricle [8].

Compelling experimental and clinical evidence suggests that the neurological deficits associated with MMC occur in stages (two-hit hypothesis) [1]. First, defective neurulation results in a neural tube defect with associated myelodysplasia. Second, subsequent exposure to the amniotic fluid, direct trauma, hydrodynamic pressure or a combination of these factors causes secondary injury to the exposed spinal cord. Theoretically, in utero coverage for protection of the cord might prevent the secondary component of the acquired damage but not the primary injury. Thus the controversy in the context of prenatal therapy arises over how much each of the two hits contributes to the observed neurological deficits and from a practical standpoint, when during fetal development the secondary damage occurs.

The objective of this paper is to discuss the rationale for fetal MMC repair in the context of pathological observations, animal models of spina bifida, short-term outcomes from initial cases of in utero closure of human fetuses as well as the recently initiated NIH-sponsored multicenter prospective randomized clinical trial, comparing outcome after in utero and postnatal surgery for spina bifida.

\section{MMC as Multifactorial Disorder}

The etiology of MMC remains poorly understood and is believed to be multifactorial. The list of variables that have been implicated as risk factors for MMC is long and varied from exposure to viruses, chemicals and drugs to vitamin and mineral deficiencies, as well as maternal diseases (i.e. diabetes mellitus) [1,9-11]. The most widely recognized trigger for MMC is a maternal and/or fetal deficiency in folic acid, an essential cofactor for enzymes involved in DNA and RNA synthesis and as a methyl donor in the methylation cycle [12]. The etiologic role of folic acid was further demonstrated by two randomized clinical trials showing that periconceptional folic acid supplementation ( $4 \mathrm{mg}$ of folic acid daily) reduces the occurrence and recurrence of MMC and other neural tube defects by approximately $70 \%[13,14]$. In addition to environmental factors, genetic and/or inherited features are implicated in the etiology of MMC [1, 9, 10, 15-18]. Several lines of evidence support the existence of a genetic predisposition for MMC including the variable incidence among ethnic groups and geographical locations, familial recurrence, genetic syndromes associated with MMC, and numerous murine models with at least 80 mutant gene loci that are associated with MMC and other neural tube defects. However, clinical genetic studies have failed to identify any single gene responsible for human MMC [19].

\section{Epidemiology}

MMC affects nearly 1 in 2,000 live births in the United States $[20,21]$. Not included in this figure are the estimated 23\% of MMC pregnancies in which the fetus is aborted [22, 23]. Mothers who choose to continue the pregnancy must prepare for a child with significant care needs and tremendous medical expense. Despite aggressive intervention, nearly $14 \%$ of all spina bifida neonates do not survive past 5 years of age, with the mortality rising to $35 \%$ in those with symptomatic brainstem dysfunction secondary to the Arnold-Chiari II malformation [24]. The Center for Disease Control (CDC) estimates that MMC and its associated abnormalities consume approximately USD 200 million in health care cost annually (in 1985 dollars) [25]. Hence MMC remains, at present, a major public health problem.

\section{Prenatal Diagnosis}

Maternal serum $\alpha$-fetoprotein and ultrasound are routinely used to identify fetuses that have or are likely to have neural tube defects [26]. Positive findings from either of these two screens are generally followed by detailed sonography, to confirm the presence of an open defect and amniocentesis, for evaluation of amniotic fluid $\alpha$-fetoprotein and acetylcholinesterase, as well as examination of fetal karyotype to rule out chromosomal anomalies [27, 28]. In affected fetuses, ultrasound is used 
to assess lower extremity configuration, position and motion, identify spine deformities and the level of the defect, the presence of the Arnold-Chiari II malformation and hydrocephalus, as well as other structural defects. In addition to ultrasound, prenatal ultrafast magnetic resonance imaging (MRI) has become a vital component for structural assessment of fetuses with MMC [29].

\section{Clinical Support for Fetal MMC Repair}

There are many observations that support the premise that fetal coverage of the MMC defect might prevent the secondary, acquired injury to the exposed spinal cord. Pathological studies of human embryos and fetuses with MMC in earlier stages of gestation show an open but undamaged neural tube with almost normal cytoarchitecture. In 1953, Patten [30] described two human embryos and one human fetus with lumbar MMC. The exposed neural elements were not neurulated but were otherwise well developed anatomically, especially in the fetus, and grossly undamaged. The lack of apparent tissue alterations led to the conclusion the spinal cord degeneration present postnatally must be a secondary and relatively late occurring process. In embryos with classical caudal myelodysplasia, Osaka et al. [31] noted that the everted neural plate retained its basic cellular orientation and that most of the membrane covering was preserved. Interestingly, Arnold-Chiari II malformation and ventriculomegaly were not present in the embryo specimens, but were found in several later-gestation MMC fetuses. In pathological examination of spinal cords of stillborn human fetuses with MMC (19-25 weeks of gestation) varying degrees of neural tissue loss at the site of the lesion were observed, but the dorsal and ventral horns were normal proximal to the defect [32]. This study was among the first to suggest the 'two-hit pathophysiology' and attributed these alterations to injuries occurring subsequent to the failure of primary neural tube formation. A study of 10 additional fetuses revealed similar findings [33]. Taken together, the above-mentioned pathological studies indicate that early stages of MMC development are characterized by nonneurulated but otherwise (near) normal neural elements. There is a consensus that the prolonged exposure of spinal cord tissue leads to secondary and rather late occurring deterioration. Finally, the typically associated malformations of the central nervous system emerge rather late in gestation.

Additional support for the 'two-hit hypothesis' comes from sonographic observation of fetuses with MMC.
Multiple studies have assessed the quality, frequency and presence of fetal leg movements during fetal development, only to report inconsistency between pre- and postnatal function [34-36]. Korenromp et al. [34] observed that fetuses with MMC exhibited leg movement at 16-17 weeks of gestation. They suggested that these affected fetuses had good function at that point in gestation. No follow-up could be reported in this series because pregnancies were interrupted. Furthermore, Sival et al. [35] compared the leg movements of 13 fetuses with MMC pre- and postnatally. Only 1 of the 13 had abnormal leg movement before birth, but 11 demonstrated abnormal leg movements postnatally. Two possible explanations for this observation exist. First, the prenatal leg movements could be secondary to spinal cord reflex rather than of cerebral origin, thus permitting motion without electrical impulses conducted through the damaged spinal cord tissue. Second, leg movement early in pregnancy could be due to cerebral function conducted through an exposed spinal cord that is not yet damaged. Most newborns with MMC show neurological impairment of the lower extremities at birth, suggesting that the neurological injury might occur later in gestation or even during delivery. Indeed, vaginal delivery has been associated with trauma to the placode and poorer function as compared with infants delivered by cesarean section. Although other studies have indicated that cesarean section for MMC may not affect neurological outcome, no group has compared vaginal delivery with elective cesarean section of vertex fetuses before onset of labor or rupture of membranes in a randomized, controlled fashion [37-40]. However, it should be noted that patients with lipomeningomyelocele, in which the neural tissue is covered and protected by skin, have almost normal lower leg and continence function, despite a neurulation abnormality that is nearly identical to that present in newborns with MMC.

\section{Experimental Support for Fetal MMC Repair}

In addition to the multiple genetic $[15,16,41-44]$ and teratogenic [45-47] models of MMC and other neural tube defects, several models of mechanical disruption of spina bifida have been described. The first was a primate model [48] in which a fetal lumbar laminectomy (L3-L5) was performed late in gestation. One group of animals was repaired immediately with allogeneic bone paste while a control group had no repair. The unrepaired fetuses showed cystic MMC-like lesions at birth and showed 
severe neurological impairment including paraplegia, incontinence, and somatosensory loss, whereas the repaired group was neurologically normal at birth. Unfortunately, the experiment did not include a period of exposure to the intrauterine environment prior to closure [48]. Heffez et al. [49] reported similar findings in fetal pigs and fetal rats. In both studies, late gestation fetuses underwent surgical creation of an MMC-like defect with immediate or delayed ( $24 \mathrm{~h}$ later) surgical closure resulting in preservation of neurological function compared to the untreated group. Notably, in some of the animals dehiscence of their skin closure occurred resulting in neurological deficit $[49,50]$. Histological examination of the exposed neural tissue revealed erosion and necrosis, findings similar to those described in children with MMC.

These studies show that exposure of the fetal spinal cord to the intrauterine environment results in significant acquired neural tissue damage with corresponding neurological deficit at birth. In addition, these studies demonstrate that closure of a surgically created MMClike lesion is feasible and improves neurological function at birth. The surgical model that is most similar to simulating the human disease is the fetal lamb model of MMC introduced by Meuli et al. [51] in 1994. The MMC-like defect was surgically created at 75 days of gestation (term $145-150$ days) by a lumbosacral laminectomy. At 100 days of gestation a reversed latissimus dorsi flap was used to cover the exposed spinal cord and the animals were delivered by cesarean section just prior term $[52,53]$. As in the primate, rat, and porcine models, the untreated fetuses showed MMC-like lesions at birth with similar neurological deficit: complete sensorimotor paraplegia, incontinence of stool and urine, and lack of sensory function of the hind limbs. In contrast, animals that underwent closure of the defect had healed skin wounds and nearnormal neurological function. Despite mild paraparesis, they were able to stand, walk, perform demanding motor test and demonstrated no signs of incontinence. Furthermore, sensory function of the hind limbs was present clinically and confirmed electrophysiologically $[52,53]$. Subsequent findings in sheep studies have shown that this model when combined with a lumber myelotomy leads to the hindbrain herniation characteristic of the Arnold-Chiari II malformation and that in utero repair restores normal hindbrain anatomy $[54,55]$.

One of the criticisms of surgical models of MMC is that the lesion is artificially created late in gestation and is therefore unable to replicate the primary defect in neurulation, limiting their experimental relevance to the 'secondary' injuries of mechanical or chemical trauma.
Therefore we recently developed and characterized a novel short-gestational animal model of isolated MMC in fetal rats by maternal administration of all-trans retinoic acid [56]. Exposure to retinoic acid at the time of posterior neuropore closure (E10 in rats) leads to a pathology that has striking morphological and clinical similarity to human MMC in approximately $60 \%$ of the fetal rats [56]. With respect to fetal surgical intervention, this animal model may facilitate investigations in the very early developmental abnormalities of spina bifida, as prenatal administration of retinoic acid induces a primary defect during the neural tube formation and allows subsequent evaluation of role of the intrauterine environment in secondary neural tissue destruction [56-58]. Furthermore, the fetal rat is large enough for surgical manipulation and has minimal propensity for preterm labor after fetal surgery, allowing the potential use of this model to study various approaches for prenatal coverage of MMC and the subsequent effect on postnatal neurological outcome.

\section{Fetal Surgical Intervention for MMC}

The overriding concern in any fetal operation is maternal safety [60]. Secondary goals are avoiding preterm labor and accomplishing the goals of the fetal intervention. Technical difficulties associated with the small size of the fetus and fragility of the fetal tissue generally limit prenatal intervention before 18 weeks of gestation, and after 32 weeks the risks of premature labor increases dramatically, so that after 32 weeks it is more reasonable to deliver the fetus first and operate on the abnormality during the neonatal period. Fetal intervention for MMC requires the coordinated effort of many specialties, including perinatologists, radiologists, pediatric surgeons and neurosurgeons, neonatologists, geneticists, an experienced operating-room team, social workers and financial counselors. The issues associated with a serious congenital malformation such as MMC are complex and emotionally challenging. Ideally at least two preoperative counseling meetings are held with the family to review the findings of diagnostic studies (i.e. ultrasound, MRI) and to provide nondirective informed consent including discussion of maternal risk and the implications of premature delivery.

Anesthetic considerations for fetal surgical intervention include maternal, fetal and uteroplacetental factors [60]. Because of physiological alterations associated with pregnancy, the mother is at risk for aspiration pneumo- 
nia, hypoxemia, and hypotension. The fetus has an immature cardiovascular system and thus is at risk for fetal asphyxia and cardiovascular collapse. Uterine relaxation is essential to expose the appropriate fetal part, prevent placental separation, and avoid preterm labor. Continuous monitoring of both fetus and mother are required. For the mother, routine monitors include electrocardiography, pulse oximetry, blood pressure cuff before induction, urinary catheter, and peripheral nerve stimulator. Fetal status is monitored by sterile intraoperative echocardiography [64].

To reduce maternal uterine activity an $\mathrm{H} 2$ antagonist the evening before and the morning of the surgery is given. Before induction, an oral antacid is given to reduce the risk of aspiration and an epidural catheter is placed for uterine relaxation and postoperative analgesia. A rapid sequence induction and intubation are accomplished. General anesthesia is maintained with $0.5 \%$ expired isoflurane and $50 \%$ nitrous oxide. Before uterine incision isoflurane is increased to $2 \%$ and titrated to uterine relaxation. In addition to the anesthesia the fetus receives via the placental circulation, the fetus receives an intramuscular injection of a narcotic just prior to the $\mathrm{MMC}$ repair. During uterine closure, magnesium sulfate is administered intravenously as a bolus and maintained intravenously for $24 \mathrm{~h}$. The isoflurane is decreased to $0.5 \% \mathrm{ex}-$ pired. After skin closure, the anesthetic agents are discontinued, and the mother is extubated. Appropriate pain medications are given through the epidural catheter and postoperative tocolytic therapy is maintained using calcium channel blockers.

The uterus is exposed through a low transverse abdominal incision and fetal and placental positions are determined by intraoperative sterile ultrasound. An autostapling device (US Surgical, Nowalk, Conn., USA) is used to create a bloodless 6 - to 8-cm hysterotomy incision a minimum of $6 \mathrm{~cm}$ away from the placental edge. Every attempted is made to maintain intrauterine volume to prevent placental separation, contraction, and expulsion of the fetus. This is accomplished by intermittent infusion of warmed $\left(37^{\circ} \mathrm{C}\right)$ lactated Ringers' solution and by exposing only the portion of the fetus that is necessary. The fetus is positioned with the MMC lesion visible through the uterine incision. The cystic membrane of the MMC is excised carefully, and the attachments of the meninges to the skin and soft tissue are detached. If possible, native dura is closed over the spinal cord as a first layer, followed by closure of the paraspinal myofascial flaps, and then the skin surrounding the lesion is carefully mobilized and closed to complete the repair (fig. 1). After completion of surgery, the uterus is closed with a tight two-layer closure and a transparent dressing is applied to the maternal abdomen to allow postoperative sonographic monitoring. Initially, patients are observed in the highrisk obstetrical unit, subsequently discharged $(\sim 4$ days postoperatively) and kept on bed rest near the hospital. Infants are delivered by planned cesarean delivery between 36 and 37 weeks after confirmation of fetal lung maturity, unless premature labor results in earlier delivery [64].

\section{Early Clinical Experience with Fetal MMC Repair}

Prior to 1997, fetal surgical intervention was considered only for fetuses with life-threatening anomalies [59, $60]$. However, the severe morbidity and significant mortality associated with MMC combined with the promising results of animal research led to consideration of prenatal intervention for this disorder.

The first cases of in utero spina bifida repair were performed in 1994 with an endoscopic technique that proved unsatisfactory and was abandoned [61]. In 1998, in utero repair of MMC was performed by hysteromy at the Vanderbilt University [62] and at the Children's Hospital of Philadelphia (CHOP) [63]. The selection criteria varied between the two institutions. At Vanderbilt, patients were not excluded based on prenatal ventricular size, late gestational age, spinal level, or presence or absence of fetal leg motion on an in utero ultrasound. At the CHOP, the fetus was only considered for surgery if the gestational age at the time of the proposed surgery was 26 weeks or less, if the ventricular diameter was less than $17 \mathrm{~mm}$, if the Arnold-Chiari II malformation was present, if the estimated level of the lesion was S1 or above, and if there was convincing leg and foot motion on ultrasound and an absence of club foot deformity [64].

The initial experience suggested that infants that were treated prenatally had improvement in hindbrain herniation as early as 3 weeks after in utero repair [65] and possibly a diminished need for shunting relative to infants that underwent standard postnatal neurosurgical repair [66]. It might be that fetal repair of MMC reduces the need for shunting by eliminating the leakage of spinal fluid that puts back pressure on the hindbrain; such treatment allows reduction of the hindbrain hernia and relieves the obstruction of the cerebrospinal fluid outflow from the fourth ventricle [8]. In a combined series of fetal surgery patients from the CHOP and Vanderbilt, 104 patients followed for at least 1 year had an overall incidence of shunt- 

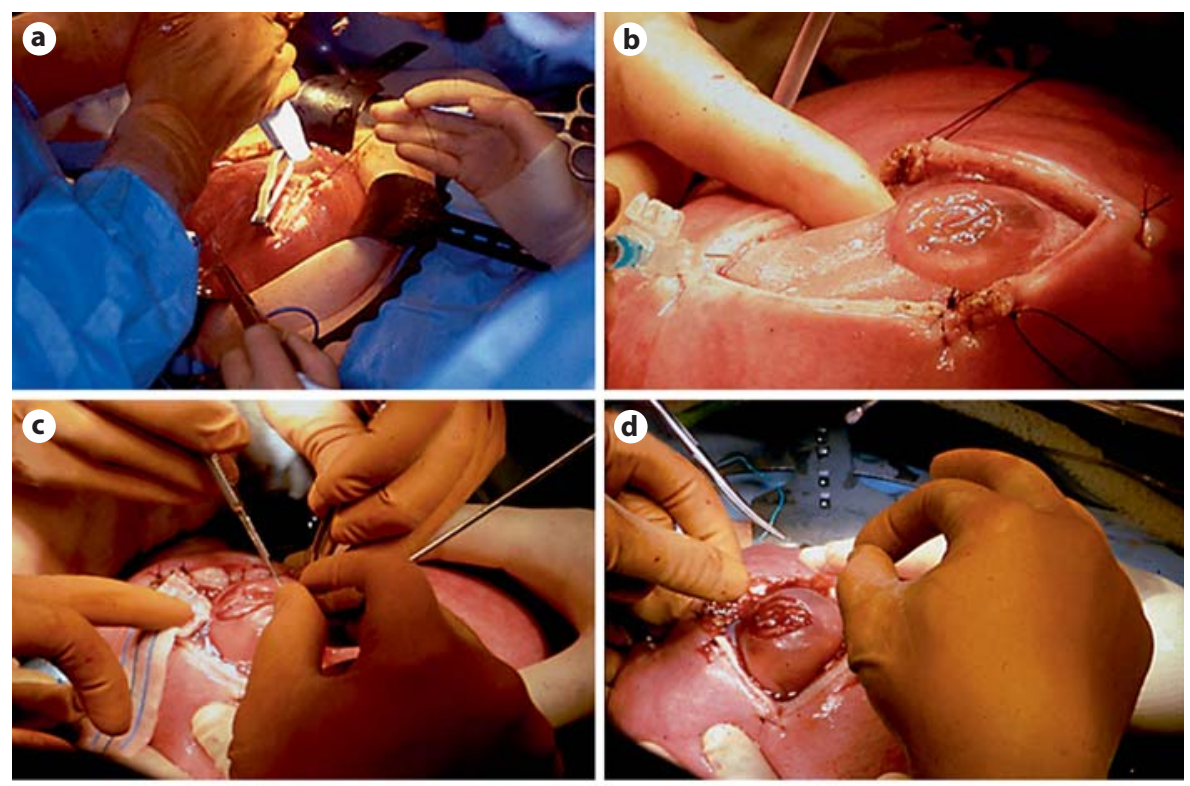

Fig. 1. Fetal MMC repair procedure. A hysterotomy is made using the uterine-stapling device (a) and the defect is positioned into the operative field (b). c The MMC sac is carefully resected and the placode is placed back into the spinal canal. The native dura is closed over the spinal cord (d) and the paraspinal muscles and skin are closed in a multilayered fashion (e).

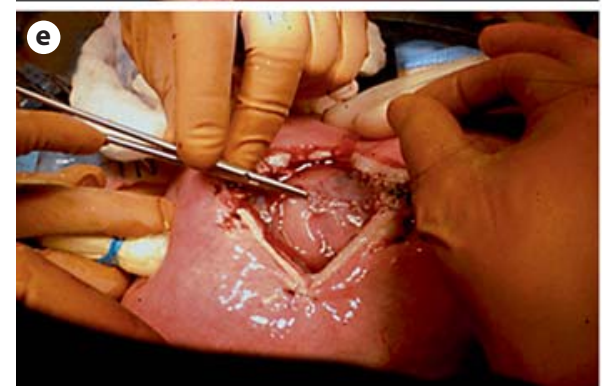

ing of 54\% [67], compared with a predicted overall shunt rate of $84 \%$ based on 297 historical controls followed up at the Spina Bifida Clinic at the CHOP between 1983 and 2000 [68]. Although long-term follow-up is necessary, the ramifications of these preliminary observations and outcomes are significant. After fetal MMC repair, ascent of the hindbrain and improved cerebrospinal fluid dynamics may reduce hydrocephalus and avert the need and morbidity of ventriculoperitoneal shunts $[64-66,69,70]$. With a more normal location of the hindbrain, the symptomatic sequelae and need for subsequent surgery should be reduced. In the case of lower lumbar and sacral lesions in which less impairment in lower extremity function may be predicted, normalizing hindbrain position and minimizing the need for postnatal ventriculoperitoneal shunt placement may be the primary indication for fetal intervention. Indeed, neurodevelopmental outcome studies of toddlers that underwent fetal MMC repair are promising, suggesting that fetal spina bifida repair might improve neurocognitive and developmental skills by decreasing the need for ventriculoperitoneal shunting [71].
Any benefit in the lower extremity function or sphincter continence has been very difficult to demonstrate. It has been recently reported that children with postnatally repaired MMC have a level of neurological function that correlates very well with the bony level of the defect [72, $73]$. In contrast to the Vanderbilt experience in late gestational fetuses (25-30 weeks) [74], lower extremity neuromotor outcome at birth was significantly improved in newborns that underwent fetal MMC before 26 weeks of gestation at the CHOP [64]. The reason for this difference may reflect patient selection, careful evaluation for evidence of intact neurological function before surgery, and younger gestational age at which the fetal repair occurred. In addition, recent reevaluation of children that underwent fetal MMC repair at the CHOP with a mean age of 40 months showed that the initial improvement in lower extremity function at birth not only persisted into preschool age, but also that fetal MMC repair results in a significant improvement of ambulatory potential (i.e. independent walking) and a reduction in the incidence of club foot deformity [75]. The impact of fetal MMC repair 
on bowel and bladder continence remains unknown, but is currently under critical evaluation [Danzer, unpubl. data].

Despite these promising findings, there is already concern that some of the early benefit of fetal MMC repair may be at risk. Virtually all of the postnatal lumbosacral MRI studies of these patients suggest tethering, and recently some of the patients have developed symptomatic epidermoid inclusion cysts which have required repeat surgery [76]. It is unclear at this point whether this is a problem unique to fetal closure or simply that it is being detected during routine surveillance after fetal surgery.

Although long-term follow-up of these patients into adulthood is necessary, the implications of the short-term outcomes after fetal MMC repair are significant, if not without controversy [77]. The potential morbidity and mortality (perinatal mortality at the CHOP due to extreme prematurity is 7\%, 4 out of 58) resulting from fetal surgery are real, and it is unclear whether the benefits in terms of shunt avoidance, reversal of hindbrain herniation, and improvement of ambulatory potential will be sustained. The optimal timing of surgery is unclear, as is the optimal type of closure. Most uncertain of all are the appropriate criteria by which patients should be selected for fetal MMC repair. In addition to the above-mentioned risk for the fetus, maternal-fetal surgery has postsurgical and future risks for the maternal patients. Potential maternal risks are surgical bleeding, infection (wound, amniotic cavity), preterm rupture of membranes, preterm labor and delivery, medication side effects (tocolysis), anesthesia complications (general, regional), prolonged hospitalization, impaired fertility, repeat cesarean deliveries, and death $[60,78]$. With respect to fetal neurosurgical intervention for MMC no maternal deaths have occurred and no patient experienced hysterotomy dehiscence or rupture. No data have been presented to suggest diminished fertility in any of the maternal patients that underwent fetal MMC.

\section{Management of MMC Study}

Due to the lack of a control group of children with MMC who did not undergo prenatal repair, the initial clinical results of in utero repair of spina bifida lesions have been compared to historical controls. Comparison between infants with spina bifida who were treated in utero and historical controls is however subject to substantial bias. Infants treated prenatally represent a highly selected subset of affected individuals. Additionally, the
Table 1. Inclusion and exclusion selection criteria for MOMS trial patients

Inclusion criteria

Maternal age $\geq 18$ years

Gestational age at randomization 19 weeks, 0 days to 25

weeks, 6 days

Normal karyotype

S1 level lesion or higher

Confirmed Arnold-Chiari II malformation on prenatal US and MRI

Exclusion criteria

Nonresident of the United States

Multifactorial pregnancy

Insulin-dependent pregestational diabetes

Additional fetal anomalies unrelated to MMC

Fetal kyphosis $\geq 30^{\circ}$

History of incompetent cervix and/or short cervix $<20 \mathrm{~mm}$ by ultrasound scan

Placenta previa

Other serious maternal medical condition

Obesity defined by body mass index of 35 or greater

Previous spontaneous singleton delivery at $<37$ weeks'

gestation

Maternal-fetal Rh isoimmunization

Positive maternal human immunodeficiency virus or

hepatitis B or known hepatitis C positivity

No support person to stay with the pregnant women at the

center

Uterine anomaly

Psychosocial limitations

Inability to comply with travel and follow-up protocols

medical management of such infants might differ from that of historical controls for reasons unrelated to the in utero repair. Taken together, it is currently unknown whether fetal surgery for MMC is truly beneficial compared to standard postnatal care. For these reasons, a National Institute of Health-sponsored multicenter, prospective, randomized, clinical trial, comparing outcome after in utero and postnatal surgery for MMC is currently underway. The study centers are the CHOP, the University of California - San Francisco, and Vanderbilt University Medical Center, along with an independent Data and Study Coordinating Center at George Washington University Biostatistics Center. The name of the trial is the Management of Myelomeningocele Study (MOMS).

Briefly, pregnant women who receive a prenatal diagnosis of MMC between 16 and 25 weeks' gestation will be referred to a central screening center. The eligibility and exclusion criteria for the MOMS trial are summarized in table 1. Eligible patients who consent to participate in the 
trial will be assigned to one of the three centers, and randomized to either fetal repair or cesarean delivery after demonstration of lung maturity. Both, in utero and standard postnatal closure of the defect will be performed at the study center by one of the three study neurosurgeons. Patients who randomize to the fetal surgery arm will stay at the study center and undergo the in utero closure. The details of closure are left largely to the discretion of the neurosurgeon based on the available tissue, but artificial graft material will not be used, except for skin closure. Relaxing incisions may be required in some instances for skin closure. Tocolytic therapy has been standardized and will be supervised by the study obstetricians. Patients will stay in the vicinity of the study center until they are medically stable.

The primary objective of the trial is to determine if intrauterine repair of fetal MMC at 19-25 weeks' gestation improves outcome, as measured by death or the need for shunting by 1 year of life compared with postnatal MMC repair. Other objectives of the study are to deter- mine if fetal MMC repair improves the degree of the Arnold-Chiari II malformation and neurological outcome as tested by neuroimaging, neuromotor function analysis, cognitive testing, and neurodevelopmental status at 12 and 30 months of life. Neonatal morbidity and the need for postnatal surgical interventions will be recorded. Finally, the long-term psychological and reproductive consequences for mothers who undergo intrauterine repair of MMC will be compared with those in the postnatal repair group. In summary, the trial should determine whether fetal intervention offers improved outcome with a reasonable quality of life for MMC children. Additional information about this trial can be obtained from the study website (www. spinabifidamoms.com).

\section{Acknowledgment}

This work was supported in part by Michael and Katherine Mulligan through the Sean Michael Mulligan Research Fund.

\section{References}

1 Danzer E, Rintoul NE, Crombleholme TM, Adzick NS: Pathophysiology of neural tube defects; in Pollin R, Fox WW, Abman SH (eds): Fetal and Neonatal Physiology, ed 3. Philadelphia, Saunders, 2003, pp 17721785.

2 Dias MS, McLone DG: Hydrocephalus in the child with dysraphism. Neurosurg Clin N Am 1993;4:715-726.

-3 Caldarelli M, DiRocco C, LaMarca F: Shunt complications in the first postoperative year in children with myelomeningocele. Childs Nerv Syst 1996;12:748-754.

4 Bell JE, Gordon A, Maloney AF: The association of hydrocephalus and Arnold-Chiari malformation with spina bifida in the fetus. Neuropathol Appl Neurobiol 1980;6:29-39.

5 Gilbert JN, Jones KL, Rorke LB, Chernoff GF, James HE: Central nervous system anomalies associated with myelomeningocele, hydrocephalus, and the Arnold-Chiari malformation: reappraisal of theories regarding the pathogenesis of posterior neural tube closure defects. Neurosurgery 1986;18: 559-564.

6 Cochrane DD, Adderley R, White CP, Norman M, Steinbok P: Apnea in patients with myelomeningocele. Pediatr Neurosurg 1990; $16: 232-239$

7 Oaks W, Gaskill S: Symptomatic Chiari malformations in childhood; in Park T (ed): Spinal Dysraphism. Boston, Blackwell Scientific Publications, 1992, pp 104-125.
8 McLone DG, Knepper PA: The cause of Chiari II malformation: a unified theory. Pediatr Neurosci 1989;15:1-12.

-9 Mitchell LE, Adzick NS, Melchionne J, Pasquariello PS, Sutton LN, Whitehead AS: Spina bifida. Lancet 2004;364:1885-1895.

10 Botto LD, Moore CA, Khoury MJ, Erickson JD: Neural-tube defects. N Engl J Med 1999; 341:1509-1519.

11 Manning SM, Jennings R, Madsen JR: Pathophysiology, prevention, and potential treatment of neural tube defects. Ment Retard Dev Disabil Res Rev 2000;6:6-14.

12 Scott JM, Weir DG, Molloy A, McPartlin J, Daly L, Kirke P: Folic acid metabolism and mechanisms of neural tube defects. Ciba Found Symp 1994;181:180-187.

13 Czeizel AE, Dudas I: Prevention of the first occurrence of neural-tube defects by periconceptional vitamin supplementation. N Engl J Med 1992;327:1832-1835.

14 MRC Vitamin Study Research Group: Pre vention of neural tube defects: results of the medical research council vitamin study. Lancet 1991;338:131-137.

15 Copp AJ, Bernfield M: Etiology and pathogenesis of human neural tube defects: insights from mouse models. Curr Opin Pediatr 1994;6:624-631.

16 Copp AJ, Greene ND, Murdoch JN: The genetic basis of mammalian neurulation. Nat Rev Genet 2003;4:784-793.
17 Copp AJ: Prevention of neural tube defects: vitamins, enzymes, and genes. Curr Opin Neurol 1998;11:97-102.

18 Harris MJ, Juriloff DM: Genetic landmarks for defects in mouse neural tube closure. Teratology 1997;56:177-187.

19 Melvin EC, George TM, Worley G, Franklin A, Mackey J, Viles K, Shah N, Drake CR, Enterline DS, Mclone D, Nye J, Oakes WJ, Mclaughlin C, Walker ML, Peterson P, Brei T, Buran C, Aben J, Ohm B, Bermans I, Qumsiyeh M, Vance, J, Pericak-Vance MA, Speer MC: Genetic studies in neural tube defects. NTD Collaborative Group. Pediatr Neurosurg 2000;32:1-9.

20 Edmonds LD, James LM: Temporal trends in the prevalence of congenital malformations at birth based on the birth defects monitoring program, United States, 1979-1987. MMWR Morb Mortal Wkly Rep 1990;39: 19-23.

21 Lary JM, Edmonds LD: Prevalence of spina bifida at birth - United States, 1983-1990: a comparison to two surveillance systems. MMWR Morb Mortal Wkly Rep 1996;45: 15-26.

22 Roberts HE, Moore CA, Cragan JD, Fernhoff PM, Khoury MJ: Impact of prenatal diagnosis on the birth prevalence of neural tube defects, Atlanta 1990-1991. Pediatrics 1995;96: 880-883. 
23 Velie EM, Shaw GM: Impact of prenatal diagnosis and elective termination on prevalence and risk estimates of neural tube defects in California, 1989-1991. Am J Epidemiol 1996;144:473-479.

24 Worly G, Schuster JM, Oakes WJ: Survival at 5 years of a cohort of newborn infants with myelomeningocele. Dev Med Child Neurol 1996;38:816-822.

-25 Goodman RA: Economic burden of spina bifida - United States, 1980-1990. MMWR Morb Mortal Wkly Rep 1989;38:264-267.

-26 Drugan A, Weissman A, Evans MI: Screening for neural tube defects. Clin Perinatol 2001;28:279-281.

-27 Brock DJ, Sutcliffe RG: Alpha-fetoprotein in antenatal diagnosis of anencephaly and spina bifida. Lancet 1972;ii:197-199.

$\checkmark 28$ Loft AG: Determination of amniotic fluid acetylcholinesterase activity in the antenatal diagnosis of foetal malformations: the first ten years. J Clin Chem Clin Biochem 1990; 28:893-911.

-29 Simon EM, Pollock AN: Prenatal and postnatal imaging of spinal dysraphism. Semin Roentgenol 2004;39:182-196.

30 Patten B: Embryological stages in the establishing of myeloschisis with spina bifida. Am J Anat 1953;93:365-395.

- 31 Osaka K, Tanimura T, Hirayama A, Matsumoto S: Myelomeningocele before birth. Neurosurg 1978;49:711-724.

-32 Hutchins GM, Meuli M, Meuli-Simmen C, Jordan MA, Heffez DS, Blakemore KJ: Acquired spinal cord injury in human fetuses with myelomeningocele. Pediatr Pathol Lab Med 1996;16:701-712.

- 33 Meuli M, Meuli-Simmen C, Hutchins GM, Seller MJ, Harrison MR, Adzick NS: The spinal cord lesion in human fetuses with myelomeningocele: implications for fetal surgery. J Pediatr Surg 1997;31:448-452.

- 34 Korenromp MJ, Van Good JD, Bruinese HW, Kriek R: Early fetal movements in myelomeningocele. Lancet 1986;i:917-918.

- 35 Sival DA, Begeer JH, Staal-Schreinemachers AL, Vos-Niel JM, Beekhuis JR, Prechtl HF: Perinatal motor behavior and neurological outcome in spina bifida aperta. Early Hum Dev 1997;50:27-37.

-36 Sival DA, Brouwer OF, Bruggink JL, Vies JS, Staal-Schreinemachers AL, Sollie KM, Sauer PJ, Bos AF: Movement analysis in neonates with spina bifida aperta. Early Hum Dev 2006;82:227-234

- 37 Shurtleff DB, Luthy DA, Nyberg DA, Benedetti TJ, Mack LA: Meningomyelocele: management in utero and post partum. Ciba Found Symp 1994;181:270-280.

- 38 Luthy DA, Wardinsky T, Shurtleff DB, Hollenbach KA, Hickok DE, Nyberg DA, Benedetti TJ: Cesarean section before the onset of labor and subsequent motor function in infants with myelomeningocele diagnosed antenatally. N Engl J Med 1991;324:662-666.
39 Merrill DC, Goodwin P, Burson JM, Sato Y, Williamson R, Weiner CP: The optimal route of delivery for fetal myelomeningocele. Am J Obstet Gynecol 1998;179:235-240.

-40 Cochrane D, Aronyk K, Sawatzky B, Wilson D, Steinbok P: The effects of labor and delivery on spinal cord function and ambulation in patients with myelomeningocele. Child Nerv Syst 1991;7:312-315.

41 Fleming A, Copp AJ: Embryonic folate metabolism and mouse neural tube defects. Science 1998;280:2107-2109.

42 Copp AJ, Brook FA, Roberts HJ: A cell-typespecific abnormality of cell proliferation in mutant (curly tail) mouse embryos developing spinal neural tube defects. Development 1988;104:285-295.

43 Van Straaten HW, Copp AJ: Curly tail: a 50year history of the mouse spina bifida model. Anat Embryol 2001;203:225-237.

44 Selcuki M, Manning S, Bernfield M: The curly tail mouse model of human neural tube defects demonstrates normal spinal cord differentiation at the level of the meningomyelocele: implications for fetal surgery. Childs Nerv Syst 2001;17:19-23.

45 Duru S, Ceylan S, Ceylan S: Comparative effects of valproic acid sodium for Chiari-like malformation at 9 and 10 days of gestation in the rat. Childs Nerv Syst 2001;17:399-404.

46 Ehlers K, Elmazar MA, Nau H: Methionine reduces the valproic acid-induced spina bifida rate in mice without altering valproic acid kinetics. J Nutr 1996;126:67-75.

47 Ehlers K, Struje H, Merker HJ, Nau H: Spina bifida aperta induced by valproic acid and by all-trans-retinoic acid in the mouse: distinct differences in morphology and periods of sensitivity. Teratology 1992;46:117-130.

48 Michejda M: Intrauterine treatment of spina bifida. Primate model. Z Kinderchir 1984; 39:259-261.

49 Heffez DS, Aryanpur J, Rotellini NA, Hutchins GM, Freeman JM: Intrauterine repair of experimental surgically created dysraphism. Neurosurgery 1993;32:1005-1010.

50 Heffez DS, Aryanpur J, Hutchins GM, Freeman JM: The paralysis associated with myelomeningocele: clinical and experimental data implicating a preventable spinal cord injury. Neurosurgery 1990;26:987-992.

51 Meuli M, Meuli-Simmen C, Yingling CD, Hoffman KB, Harrison MR, Adzick NS: A new model of myelomeningocele: studies in the fetal lamb. Surg Forum 1994;45:587589.

52 Meuli M, Meuli-Simmen C, Hutchins GM, Yingling CD, Hoffman KM, Harrison MR, Adzick NS: In utero surgery rescues neurologic function at birth in sheep with spina bifida. Nat Med 1995;1:342-347.

53 Meuli M, Meuli-Simmen C, Hutchins GM, Yingling CD, Hutchins GM, Timmel GB, Harrison MR, Adzick NS: In utero repair of experimental myelomeningocele spares neurologic function at birth. J Pediatr Surg 1996; 31:397-402.
54 Paek BW, Farmer DL, Wilkinson CC, Albanese CT, Peacook W, Harrison MR, Jennings RW: Hindbrain herniation develops in surgically created myelomeningocele but is absent after repair in fetal lambs. Am J Obstet Gynecol 2000;183:1119-1123.

55 Bouchard S, Davey MG, Rintoul NE, Walsh DS, Rorke LB, Adzick NS: Correction of hindbrain herniation and anatomy of the vermis following in utero repair of myelomeningocele in sheep. J Pediatr Surg 2003;38: 451-458.

56 Danzer E, Schwarz U, Wehrli S, Radu A, Adzick NS, Flake AW: Retinoic acid induced myelomeningocele in fetal rats: characterization by histopathological analysis and magnetic resonance imaging. Exp Neurol 2005; 194:467-475.

-57 Danzer E, Kiddoo DA, Redden RA, Robinson L, Radu A, Zderic SA, Doolin EJ, Adzick NS, Flake AW: Structural and functional characterization of bladder smooth muscle in fetal rats with retinoic acid induced myelomeningocele. Am J Physiol Renal Physiol 2007;292:197-206.

-58 Danzer E, Radu A, Volpe MA, Adzick NS, Flake AW: Normal neuromuscular development of the lower gastrointestinal tract and anorectum in fetal rats with retinoic acid induced myelomeningocele - implications for fetal surgery. J Am Coll Surg 2006;203:S36.

- 59 Adzick NS, Harrison MR: Fetal surgical therapy. Lancet 1994;343:897-902.

-60 Danzer E, Sydorak RM, Harrison MR, Albanese CT: Minimal access fetal surgery. Eur J Obstet Gynecol Reprod Biol 2003;108:3-13.

61 Bruner J, Tulipan N, Richards W: Endoscopic coverage of fetal open myelomeningocele in utero. Am J Obstet Gynecol 1997;176:256257.

62 Tulipan N, Bruner JP: Myelomeningocele repair in utero: a report of three cases. Pediatr Neurosurg 1998;28:177-180.

63 Adzick NS, Sutton LN, Crombleholme TM, Flake AW: Successful fetal surgery for spina bifida. Lancet 1998;352:1675-1676.

64 Johnson MP, Sutton LN Rintoul N, Crombleholme TM, Flake AW, Howell LJ, Hedrick HL, Wilson RD, Adzick NS: Fetal myelomeningocele repair: short-term clinical outcomes. Am J Obstet Gynecol 2003;189:482487.

65 Sutton LN, Adzick NS, Bilaniuk LT, Johnson MP, Crombleholme TM, Flake AW: Improvement in hindbrain herniation demonstrated by serial fetal magnetic resonance imaging following fetal surgery for myelomeningocele. JAMA 1999;282:1826-1831.

66 Bruner JP, Tulipan N, Paschall RL, Boehm FH, Walsh WF, Silvia SR, Hernanz-Schulman M, Lowe LH, Reed GW: Fetal surgery for myelomeningocele and the incidence of shunt-dependent hydrocephalus. JAMA 1999;282:1819-1825. 
67 Tulipan N, Sutton LN, Bruner JP, Cohen BM, Johnson M, Adzick NS: The effect of intrauterine myelomeningocele repair on the incidence of shunt-dependent hydrocephalus. Pediatr Neurosurg 2003;38:27-33.

-68 Rintoul NE, Sutton LN, Hubbard AM, Cohen B, Melchionni J, Pasquariello PS, Adzick NS: A new look at myelomeningoceles: functional level, vertebral level, shunting, and the implications for fetal intervention. Pediatrics 2002;109:409-413.

-69 Danzer E, Johnson MP, Wilson RD, Flake AW, Hedrick HL, Sutton LN, Adzick NS: fetal head biometry following in-utero repair of myelomeningocele. Ultrasound Obstet Gynecol 2004;24:606-611.

70 Danzer E, Johnson MP, Bebbington M, Simon EM, Wilson RD, Bilaniuk LT, Sutton LN, Adzick NS: Fetal head biometry assessed by fetal magnetic resonance imaging following in utero myelomeningocele repair. Fetal Diagn Ther 2007;22:1-6.
71 Johnson MP, Gerdes M, Rintoul N, Pasquariello P, Melchionni J, Sutton LN, Adzick NS Maternal-fetal surgery for myelomeningocele: neurodevelopmental outcomes at 2 years of age. Am J Obstet Gynecol 2006;194 1145-1150.

72 Kollias SS, Goldstein RB, Cogen PH, Filly RA: Prenatally detected myelomeningoceles: sonographic accuracy in estimation of the spinal levels. Radiology 1992;185:109-112.

73 Biggio JR, Owen J, Wenstrom KD, Oakes WJ: Can prenatal ultrasound findings predict ambulatory status in fetuses with open spina bifida? Am J Obstet Gynecol 2001;185:10161020.

74 Tubbs S, Chambers MR, Smyth MD, Bartolucci AA, Bruner JP, Tulipan N, Oakes WJ: Late gestational intrauterine myelomeningocele repair does not improve lower extremity function. Pediatr Neurosurg 2003 38:128-132.
75 Danzer E, Adzick NS, Gerdes M, Bebbington MW, Sutton LN, Melchionni J, Johnson MP: Lower extremity neuromotor function following in utero myelomeningocele repair. Am J Obstet Gynecol 2006;195:S22.

-76 Mazzola C, Albright AL, Sutton LN, Tuite GF, Hamilton RL, Pollack IF: Dermoid inclusion cysts and early spinal cord tethering after fetal surgery for myelomeningocele. $\mathrm{N}$ Engl J Med 2002;347:256-259.

77 Simpson JL: Fetal surgery for myelomeningocele: promise, progress, and problems. JAMA 1999;282:1873-1874.

78 Wilson RD, Johnson MP, Flake AW, Crombleholme TM, Hedrick HL, Wilson J, Adzick NS: Reproductive outcomes after pregnancy complicated by maternal-fetal surgery. Am J Obstet Gynecol 2004;191:1430-1436. 